\title{
Regio- and stereoselective synthesis of new diaminocyclopentanols
}

\author{
Evgeni A. Larin ${ }^{*}$, Valeri S. Kochubei ${ }^{1}$ and Yuri M. Atroshchenko ${ }^{2}$
}

\section{Full Research Paper}

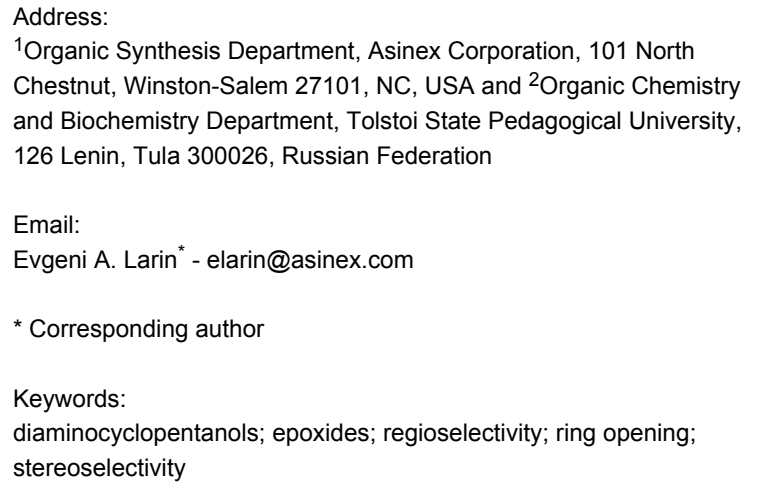

Beilstein J. Org. Chem. 2014, 10, 2513-2520. doi:10.3762/bjoc. 10.262

Received: 08 June 2014 Accepted: 16 October 2014 Published: 28 October 2014 Associate Editor: J. Aubé

(c) 2014 Larin et al; licensee Beilstein-Institut. License and terms: see end of document.

\begin{abstract}
The optimal conditions for regio- and stereoselective epoxide ring opening of $N, N$-disubstituted 1,2-epoxy-3-aminocyclopentanes by different nucleophilic reagents have been developed. The substituents on the nitrogen atom in the epoxide precursor and the orientation of the oxirane ring are crucial for the reaction outcome. Thus, treatment of (1RS,2SR,3SR)-1,2-epoxy-3-( $N, N$-dibenzylamino)cyclopentane (3b) with amines gave a mixture of $\mathrm{C} 1$ and $\mathrm{C} 2$ regioadducts, while the use of (1RS,2SR,3SR)-1,2-epoxy-3-(Nbenzyl- $N$-methylamino)cyclopentane (3a) led ultimately to $\mathrm{C} 1$ adducts. Base-catalyzed aminolysis of epoxides 6a,b afforded mainly $\mathrm{C} 1$ adducts $\mathbf{1 3 a} \mathbf{a}, \mathbf{b}$ arising from trans-diaxal opening of the epoxide ring. Using a Lewis acid catalyst, epoxides $\mathbf{6 a}, \mathbf{b}$ were transformed into diaminocyclopentanols $\mathbf{1 4 a}, \mathbf{b}$ via an alternative pathway involving the formation of aziridinium intermediate 17.
\end{abstract}

\section{Introduction}

In recent years mimicry of aminoglycosides [1-7] and nucleosides [8-10] has become an important field in pharmaceutical research. Regio- and stereochemical diversities within a sugarlike moiety in those mimics may subtly influence their biological activity [11-14]. The functionalization of synthetic, unnatural aminocyclitols represents an attractive strategy towards the preparation of aminoglycoside and nucleoside mimics, and the development of common synthesis routes to various regio- and stereoisomeric aminocyclitol derivatives remains in demand. One of the optimal routes involves the stereoselective ring opening of epoxides by different nucleophiles in the presence of a variety of activators [15-19]. In this context, epoxidation of cyclic allylic amines and subsequent oxirane ring opening represent a viable approach for the development of new pharmaceutically relevant scaffolds.

As a part of our ongoing research in the development of new aminocyclitols, we exploited cyclopentane derivatives to mimic both the 2-deoxystreptamine ring, a core component in aminoglycosides [7], and nucleosides containing $9 H$-purin-6-amine as 
a nucleobase portion. High levels of stereoselectivity have been observed in substrate-controlled diastereoselective epoxidation of cyclic alkenes with $O$ - and $N$-allylic directing groups [20,21]. Several 3-substituted diastereomeric epoxides have recently been synthesized via the ammonium-directed olefinic oxidation of cyclic allylic amines. It has been reported that functionalization of a range of allylic 3-(N,N-dibenzylamino)cycloalkenes with $m$-CPBA in the presence of trichloroacetic acid gave exclusively corresponding syn-epoxides [22]. Examples of stereoselective epoxide opening of these cyclic amine derivatives are limited to the preparation of the corresponding diols under acidic conditions [23]. Other reported strategies involve the formation of diaminocyclohexanols from epoxides under basic conditions [24] or by activating the epoxides with hydrogen bond donors [25]. Additionally, the synthesis of aminocyclitols from cyclitol epoxides has been described $[26,27]$. It has been shown that the reaction of cyclitol epoxides with nitrogen-containing nucleophiles in the presence of Lewis acids gave a mixture of $\mathrm{C} 1$ and $\mathrm{C} 2$ adducts. Both epoxide carbons can react with a nucleophile to produce regioisomeric aminocyclitols. Herein, we describe the regio- and stereoselective synthesis of diaminocyclopentanol derivatives from $N$-protected cyclopentanamine epoxides using nitrogencontaining nucleophiles.

\section{Results and Discussion Preparation of starting epoxides}

Epoxides 3a,b (Scheme 1) were obtained by the addition of benzyl(methyl)amine or dibenzylamine to cyclopent-2-en-1-yl acetate (1) followed by epoxidation [28]. Epoxides $\mathbf{6 a , b}$ were synthesized from 3a,b through epoxide ring inversion using glacial acetic acid as the oxirane-cleaving agent [29].

The treatment of the corresponding acetates 4 with mesyl chloride and subsequent transesterification of mesylated substrates 5 resulted in the formation of $\mathbf{6 a}, \mathbf{b}$. Epoxides $\mathbf{3}$ and $\mathbf{6}$ were identi- fied by ${ }^{1} \mathrm{H}$ NMR data [28]. Morpholine (7a), 2-methyl-1Himidazole (7b), $\mathrm{N}$-acetylpiperazine (7c) and $9 \mathrm{H}$-purin-6-amine (7d) were used as nucleophiles (Figure 1). Starting amines were selected based on the fact that these motifs are common structural features in drug molecules.

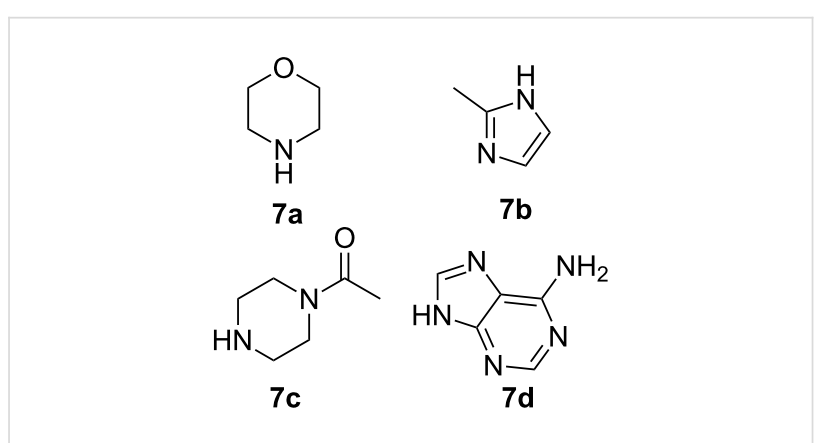

Figure 1: Amine-based nucleophiles used in the epoxide ring opening reaction.

\section{Optimization of the epoxide ring opening reaction of $\mathbf{3 a}$}

The opening of epoxides with nucleophiles in the presence of Lewis acid or base promoters is well documented [30-34]. We conducted a number of experiments to optimize the ring opening in 3a (Table 1). The initial catalytic epoxide ringopening experiments of $\mathbf{3 a}$ in $\mathrm{MeCN}$ at $80{ }^{\circ} \mathrm{C}$ [35] were unsuccessful, since only starting material was recovered. A series of experiments was performed under solvent-free conditions at $100{ }^{\circ} \mathrm{C}$. In case of morpholine (7a), the best catalytic effect was observed with $\mathrm{LiClO}_{4}$ [36] and $\mathrm{Zn}\left(\mathrm{ClO}_{4}\right)_{2} \cdot 6 \mathrm{H}_{2} \mathrm{O}$ [37] affording 56 and $76 \%$ yield of $8 \mathbf{a}$ after isolation and purification, therefore the absence of the solvent seems crucial for the reaction outcome (Table 1, entries 2 and 3).

On the contrary, the epoxide ring opening of 3a with 2-methyl$1 \mathrm{H}$-imidazole (7b) in the presence of Lewis acid catalysts

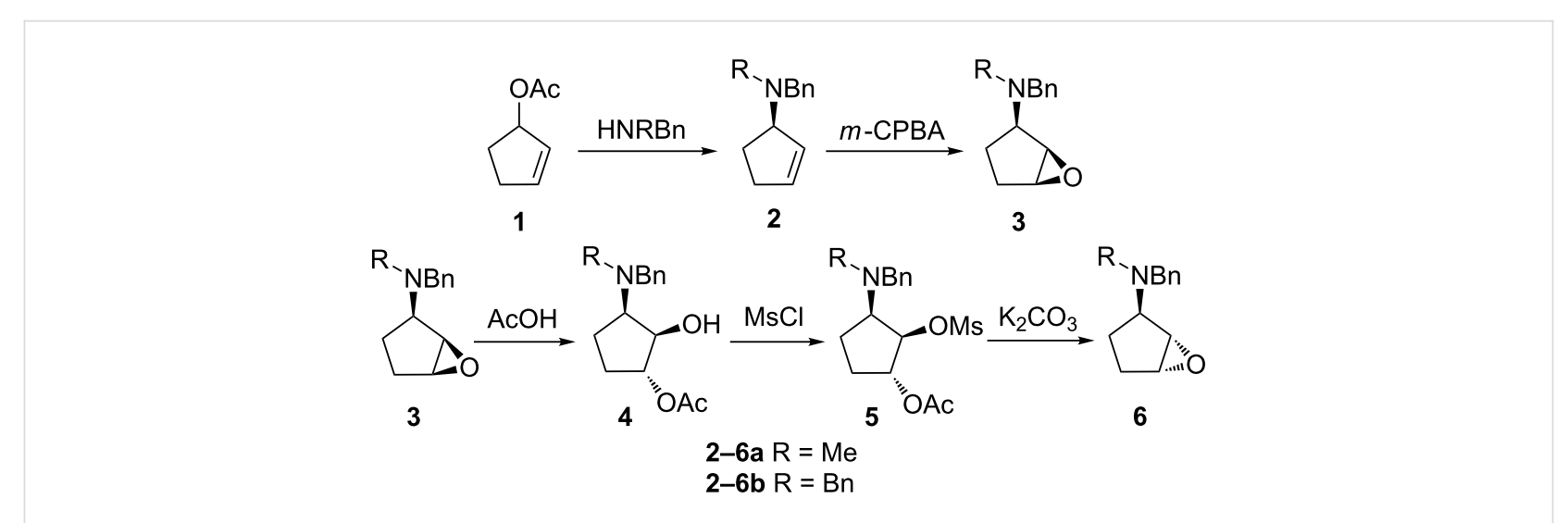


Table 1: Reactions of $3 a$ with nucleophiles in the presence of various catalysts.

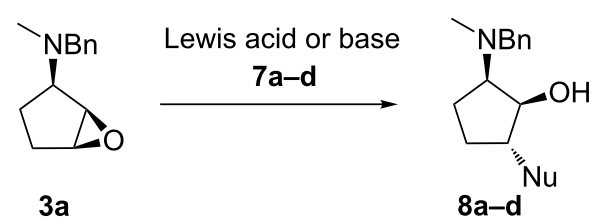

\begin{tabular}{|c|c|c|c|c|c|}
\hline Entry & $\mathrm{Nu}$ & Catalyst & 8 & Yield $(\%)^{a, b}$ & Yield $(\%)^{b, c}$ \\
\hline 1 & $7 a$ & $\mathrm{ZrCl}_{4}$ & $8 a$ & $14^{d}$ & traces \\
\hline 2 & $7 a$ & $\mathrm{LiClO}_{4}$ & $8 a$ & 56 & - \\
\hline 3 & $7 a$ & $\mathrm{Zn}\left(\mathrm{ClO}_{4}\right)_{2} \cdot 6 \mathrm{H}_{2} \mathrm{O}$ & $8 a$ & 76 & 5 \\
\hline 4 & $7 a$ & $\mathrm{Bi}(\mathrm{OTf})_{3}$ & $8 a$ & 5 & traces \\
\hline 5 & $7 a$ & $\mathrm{Cs}_{2} \mathrm{CO}_{3}$ & $8 a$ & - & traces \\
\hline 6 & $7 a$ & $\mathrm{~K}_{2} \mathrm{CO}_{3}$ & $8 a$ & - & - \\
\hline 7 & $7 b$ & $\mathrm{ZrCl}_{4}$ & $8 b$ & traces $^{d}$ & traces $^{d}$ \\
\hline 8 & $7 b$ & $\mathrm{LiClO}_{4}$ & $8 b$ & 27 & - \\
\hline 9 & $7 b$ & $\mathrm{Zn}\left(\mathrm{ClO}_{4}\right)_{2} \cdot 6 \mathrm{H}_{2} \mathrm{O}$ & $8 b$ & 21 & - \\
\hline 10 & $7 b$ & $\mathrm{Bi}(\mathrm{OTf})_{3}$ & $8 b$ & 53 & $24^{d}$ \\
\hline 11 & $7 b$ & $\mathrm{Cs}_{2} \mathrm{CO}_{3}$ & $8 b$ & 61 & 75 \\
\hline 12 & $7 b$ & $\mathrm{~K}_{2} \mathrm{CO}_{3}$ & $8 b$ & 38 & $16^{d}$ \\
\hline 13 & 7c & $\mathrm{Zn}\left(\mathrm{ClO}_{4}\right)_{2} \cdot 6 \mathrm{H}_{2} \mathrm{O}$ & $8 c$ & 44 & 7 \\
\hline 14 & $7 d$ & $\mathrm{Cs}_{2} \mathrm{CO}_{3}$ & $8 d$ & - & 65 \\
\hline
\end{tabular}

aReagents and conditions: $5.0 \mathrm{mmol}$ epoxide, $10.0 \mathrm{~mol} \%$ catalyst, $6.5 \mathrm{mmol}$ nucleophile, neat, $100{ }^{\circ} \mathrm{C}, 2 \mathrm{~h} .{ }^{\mathrm{b}}$ Isolated yield. ${ }^{\mathrm{c}} \mathrm{Reagents}$ and conditions: $5.0 \mathrm{mmol}$ epoxide, $10.0 \mathrm{~mol} \%$ catalyst, $6.5 \mathrm{mmol}$ nucleophile, DMSO $(10 \mathrm{~mL}), 120{ }^{\circ} \mathrm{C}, 2 \mathrm{~h}$. ${ }^{\mathrm{d}}$ Reaction time $4 \mathrm{~h}$.

produced $\mathbf{8 b}$ in low yields (Table 1, entries 7-9), except for the reaction in the presence of $\mathrm{Bi}(\mathrm{OTf})_{3}$ [38] (Table 1, entry 10). In this case, we planned to evaluate the catalytic efficiency of base promoters such as $\mathrm{Cs}_{2} \mathrm{CO}_{3}$ and $\mathrm{K}_{2} \mathrm{CO}_{3}$ [39-41]. The best result was obtained with $\mathrm{Cs}_{2} \mathrm{CO}_{3}$ using DMSO as a solvent (Table 1, entry 11). The catalytic effect of $\mathrm{Cs}_{2} \mathrm{CO}_{3}$ could be explained by its ability to increase the poor nucleophilicity of 2-methyl- $1 \mathrm{H}$ imidazole (7b). Eventually, $\mathrm{Zn}\left(\mathrm{ClO}_{4}\right)_{2} \cdot 6 \mathrm{H}_{2} \mathrm{O}$ and $\mathrm{Cs}_{2} \mathrm{CO}_{3}$ were selected as the catalysts for further experiments. These conditions were applied for aminolysis of $\mathbf{3 a}$ with $\mathrm{N}$-acetylpiperazine (7c) and 9H-purin-6-amine (7d) (Table 1, entries 13 and 14) to provide 44 and $65 \%$ yields of the corresponding aminocyclopentanols 8c and 8d (Supporting Information File 1).

In every experiment, 1,2-trans-2,3-cis-aminocyclopentanols, arising from opening of epoxide $\mathbf{3 a}$ at $\mathrm{C} 1$, were the only regioisomers isolated. The stereo- and regiochemistry of $\mathbf{8 a}$ and $\mathbf{8 d}$ were assigned by 2D NMR (HSQC-DEPT, ${ }^{1} \mathrm{H},{ }^{1} \mathrm{H}$ COSY and NOESY experiments). The 2D carbon-proton chemical shift correlation study on $8 \mathbf{a}$ showed that the proton resonances at $\delta$ $2.43-2.46,2.55$ and 3.90 correspond to methylene groups, and that these resonances can be assigned by $\mathrm{C}(1) \mathrm{H}-\mathrm{OH}$ and $\mathrm{C}(2) \mathrm{H}$ $\mathrm{NCH}_{3} \mathrm{COSY}$ correlations. The presence of the $\mathrm{C}(1) \mathrm{H}-\mathrm{C}(2) \mathrm{H}$ correlation and the absence of the $\mathrm{C}(2) \mathrm{H}-\mathrm{C}(5) \mathrm{H}$ correlation in the NOESY spectrum support the stereochemistry of $\mathbf{8 a}$. The same relative configuration of $\mathbf{8 d}$ was assigned from 2D NMR analysis, and the stereochemistry of $\mathbf{8 b}$ and $\mathbf{8 c}$ was additionally confirmed by the comparison of ${ }^{3} J$ coupling constants of the resonances corresponding to $\mathrm{C}(1) \mathrm{H}, \mathrm{C}(2) \mathrm{H}$ and $\mathrm{C}(5) \mathrm{H}$ (Supporting Information File 2). Therefore, spectral data

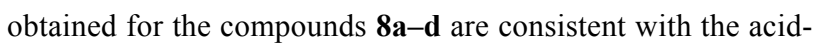
catalyzed trans-diaxial epoxide opening, proceeding via a latetransition state, and the $N$-benzyl- $N$-methylammonium moiety promotes the nucleophilic attack at the $\mathrm{C} 1$-oxirane carbon atom [29].

\section{Synthesis of diaminocyclopentanols using epoxide $\mathbf{3 b}$}

Next, we explored the influence of the $N, N$-dibenzylamino group on the ring opening reaction using the optimized reaction conditions for $\mathbf{3 b}$ (Table 2). Surprisingly, the ring opening of $N, N$-dibenzyl derivative $\mathbf{4 b}$ displayed poor regioselectivity. In fact, a mixture of the separable regioisomers $\mathbf{9 a - d}$ and $\mathbf{1 0 a}-\mathbf{d}$ were obtained, where the major products $\mathbf{9 a - d}$ were formed due to the attack of the nucleophile at the $\mathrm{C} 1$-oxirane carbon atom.

In case of aliphatic cyclic amines (morpholine (7a) and $\mathrm{N}$-acetylpiperazine (7c)), the best regioisomeric ratio (2:1) was observed using $\mathrm{Zn}\left(\mathrm{ClO}_{4}\right)_{2} \cdot 6 \mathrm{H}_{2} \mathrm{O}$ as a catalyst (Table 2, entries 1 
Table 2: Regioselectivity in the epoxide ring opening of $\mathbf{3 b}$ with nucleophiles.

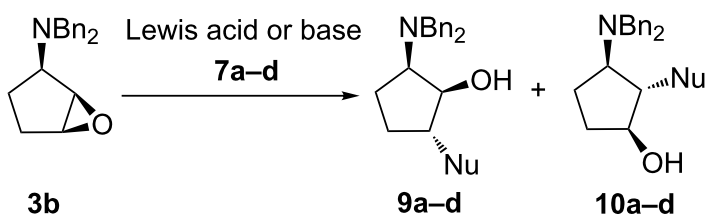

\begin{tabular}{|c|c|c|c|c|c|}
\hline Entry & $\mathrm{Nu}$ & Catalyst & Product & Yield $(\%)^{a, b}$ & $\mathrm{rr}^{\mathrm{C}}(9: 10)$ \\
\hline \multirow[t]{2}{*}{1} & $7 a$ & $\mathrm{Zn}\left(\mathrm{ClO}_{4}\right)_{2} \cdot 6 \mathrm{H}_{2} \mathrm{O}$ & $9 a$ & 48 & $2: 1$ \\
\hline & & & $10 a$ & 24 & \\
\hline \multirow[t]{2}{*}{2} & $7 a$ & $\mathrm{LiClO}_{4}$ & $9 a$ & 50 & $8: 5$ \\
\hline & & & $10 a$ & 31 & \\
\hline \multirow[t]{2}{*}{3} & $7 b$ & $\mathrm{Cs}_{2} \mathrm{CO}_{3}$ & $9 b$ & 47 & $7: 3$ \\
\hline & & & $10 b$ & 20 & \\
\hline \multirow[t]{2}{*}{4} & $7 b$ & $\mathrm{Cs}_{2} \mathrm{CO}_{3}$ & $9 b$ & $64^{d}$ & $2: 1$ \\
\hline & & & $10 b$ & $26^{d}$ & \\
\hline \multirow[t]{2}{*}{5} & 7c & $\mathrm{Zn}\left(\mathrm{ClO}_{4}\right)_{2} \cdot 6 \mathrm{H}_{2} \mathrm{O}$ & $9 c$ & 43 & $2: 1$ \\
\hline & & & $10 c$ & 21 & \\
\hline \multirow[t]{2}{*}{6} & $7 c$ & $\mathrm{LiClO}_{4}$ & $9 c$ & $45^{d}$ & $9: 5$ \\
\hline & & & $10 c$ & $25^{d}$ & \\
\hline \multirow[t]{2}{*}{7} & $7 d$ & $\mathrm{Cs}_{2} \mathrm{CO}_{3}$ & $9 d$ & 46 & $2: 1$ \\
\hline & & & $10 d$ & 23 & \\
\hline
\end{tabular}

aReagents and conditions: $5.0 \mathrm{mmol}$ epoxide, $10.0 \mathrm{~mol} \%$ catalyst, $6.5 \mathrm{mmol}$ nucleophile, neat, $100{ }^{\circ} \mathrm{C}, 2 \mathrm{~h}$. ${ }^{\mathrm{b}}$ Isolated yield. ${ }^{\mathrm{C}}$ Regioisomeric ratio for separated isomers. ${ }^{d}$ Reactions were performed in DMSO at $120^{\circ} \mathrm{C}$.

and 5). The use of $\mathrm{LiClO}_{4}$ led to lower regioselectivity (Table 2, entries 2 and 6). Apparently, the nature of the catalyst and the ability of the metal ion to coordinate with the oxirane oxygen have no significant influence on the regioisomeric ratio (rr). The reactions of $\mathbf{3 b}$ with 2 -methyl- $1 \mathrm{H}$-imidazole (7b) and $9 \mathrm{H}$-purin6-amine (7d) in the presence of $\mathrm{Cs}_{2} \mathrm{CO}_{3}$ in DMSO showed the same regioselectivity (Table 2, entries 4 and 7), indicating that the epoxide opening reactions are not directed by the amine nucleophilicity. Moreover, there was not much effect on the outcome of the reactions conducted either under solvent-free conditions or using DMSO as a solvent.

The regioisomers $\mathbf{9 a}-\mathbf{d}$ and $\mathbf{1 0 a}-\mathbf{d}$ were isolated through column chromatographic separation and fully characterized in order to avoid ambiguity. The stereochemistry of the major regioisomers 9a-d was deduced from the analysis of ${ }^{1} \mathrm{H}$ NMR and 2D NMR data as described for 8a-d. Assignments of $\mathrm{CH}$ proton resonances of $\mathbf{1 0 a}-\mathbf{d}$ were established by ${ }^{1} \mathrm{H},{ }^{13} \mathrm{C} \mathrm{HMBC}$ and HSQC-DEPT experiments, and connectivity was established by the analysis of ${ }^{1} \mathrm{H},{ }^{1} \mathrm{H}$ COSY spectra. The structures of $10 \mathrm{a}$ and 10c were elucidated based on COSY correlation of $\mathrm{C}(1) \mathrm{H}-\mathrm{OH}$ resonances at $\delta 3.88$ for $\mathbf{1 0 a}$ and 3.85 for $\mathbf{1 0 c}$. ${ }^{1} \mathrm{H}$ NMR NOESY analyses of 10a and 10c facilitated the initial assignment of the relative configuration. Thus, the values of
$\mathrm{C}(1) \mathrm{H}-\mathrm{C}(3) \mathrm{H}, \mathrm{C}(2) \mathrm{H}-\mathrm{OH}$ and $\mathrm{C}(3) \mathrm{H}-\mathrm{CH}_{2} \mathrm{~N}$ NOEs were quite diagnostic. $\mathrm{C}(1) \mathrm{H}$ proton resonances were observed at $\delta$ 3.84-3.95 for $\mathbf{1 0 b}$ and 4.53 for $\mathbf{1 0 d}$. $\mathrm{C}(2) \mathrm{H}$ and $\mathrm{C}(3) \mathrm{H}$ resonances appeared as doublets of doublets at $\delta 4.20(J=9.3$ and $7.8 \mathrm{~Hz})$ and $3.38(J=17.7$ and $8.6 \mathrm{~Hz})$ for $\mathbf{1 0 b}$ and at $\delta 4.61$ $(J=9.8$ and $7.9 \mathrm{~Hz})$ and $3.71(J=18.3$ and $8.7 \mathrm{~Hz})$ for $\mathbf{1 0 d}$. $\mathrm{C}(2) \mathrm{H}-\mathrm{C}(3) \mathrm{H}, \mathrm{C}(1) \mathrm{H}-\mathrm{OH}, \mathrm{C}(2) \mathrm{H}-\mathrm{C}(1) \mathrm{H}$ COSY correlations and $\mathrm{C}(1) \mathrm{H}-\mathrm{C}(3) \mathrm{H}, \mathrm{C}(2) \mathrm{H}-\mathrm{OH}, \mathrm{C}(2) \mathrm{H}-\mathrm{CH}_{2} \mathrm{Ph}$ NOEs indicated the relative 1,2-anti-2,3-anti-configurations of $\mathbf{1 0 b}$ and $\mathbf{1 0 d}$ (Supporting Information File 2).

In order to investigate the influence of different substituents on the nitrogen atom on the regioselective outcome, epoxides $\mathbf{3 c}$ and $\mathbf{3 d}$ were additionally synthesized, and the results are summarized in Table 3.

It has been proposed earlier that the coordination of the Lewis acid to both oxygen atoms in 2,3-epoxy alcohols and acids leads to the formation of the intermediate complex, for which nucleophiles attack preferably the $\mathrm{C} 3$ position $[42,43]$. The electron donating methyl group in 3a seems to improve the binding of the Lewis acid to the nitrogen atom, favoring the formation of the $\mathrm{C} 1$-adduct, and the lower basicity of the dibenzylamino moiety in $\mathbf{3 b}$ may lead to the diminished coordination of Lewis 
Table 3: Epoxide ring opening of 3a-d containing different substituents on the nitrogen atom.

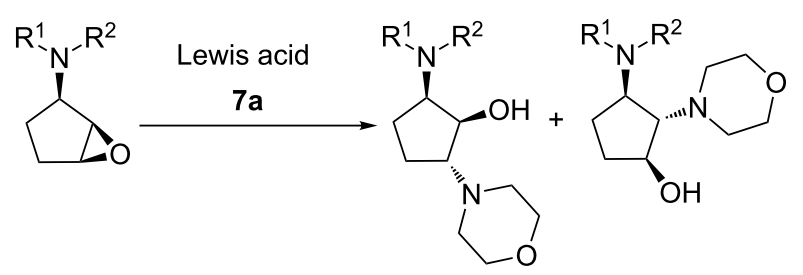

3a-d $8 a, 9 a, 11 \quad 10 a, 12$

\begin{tabular}{|c|c|c|c|c|c|c|c|}
\hline Entry & Epoxide & $\mathrm{R}^{1}$ & $\mathrm{R}^{2}$ & Reaction time, $\mathrm{h}^{\mathrm{a}}$ & Product $(\mathrm{C} 1)^{\mathrm{b}}$ & Product $(\mathrm{C} 2)^{\mathrm{b}}$ & $\operatorname{rr}(\mathrm{C} 1: \mathrm{C} 2)$ \\
\hline 1 & $3 a$ & $\mathrm{Me}$ & $\mathrm{Bn}$ & 2 & $8 a$ & - & $>19: 1$ \\
\hline 2 & $3 b$ & $\mathrm{Bn}$ & $\mathrm{Bn}$ & 2 & $9 a$ & $10 a$ & $2: 1$ \\
\hline 3 & $3 c$ & $\mathrm{Ph}$ & $\mathrm{Bn}$ & 6 & 11 & 12 & $5: 1^{c}$ \\
\hline 4 & $3 d$ & $\mathrm{Ph}$ & $\mathrm{Ph}$ & $6^{d}$ & - & - & - \\
\hline
\end{tabular}

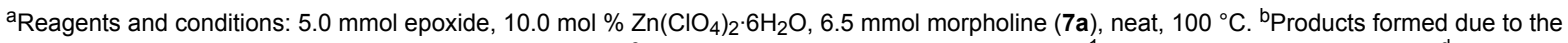
nucleophilic attack at the $\mathrm{C} 1$ or $\mathrm{C} 2$ oxirane carbon atoms. ${ }^{\mathrm{C}}$ The regiochemistry was established from ${ }^{1} \mathrm{H}$ NMR analysis of the mixture. ${ }^{\mathrm{d}} \mathrm{No}$ reaction was observed.

acid and hence the lower regioselectivity (Table 3, entries 1 and 2). Unexpectedly, using 3c, with an electron withdrawing phenyl group on the nitrogen atom, provided higher regioselectivity towards the $\mathrm{C} 1$-adduct ( $\mathrm{rr} 5: 1$ ) in comparison with $\mathbf{3 b}$ (Table 3, entries 2 and 3). The structure of the major regioisomer 11 was established by the analysis of ${ }^{1} \mathrm{H}$ NMR and ${ }^{1} \mathrm{H},{ }^{1} \mathrm{H}$ COSY data (Supporting Information File 2). This fact can be explained by the suggestion that despite the induced binding of the Lewis acid to the nitrogen atom due to the negative inductive effect of the phenyl substituent, the intermediate complex is likely to be stabilized by the $\pi$ electrons of the phenyl ring, which leads to the formation of $\mathbf{1 1}$ as a major product. However, the presence of electron withdrawing substituents on the nitrogen atom and, as a result, the diminished coordination of the Lewis acid required the longer reaction time (6 h), while in case of $\mathbf{3 d}$ bearing two phenyl groups no epoxide ring opening was observed (Table 3, entries 3 and 4).

\section{Ring opening reactions for epoxides $\mathbf{6} \mathbf{a}, \mathbf{b}$}

Ring opening of epoxides $\mathbf{6 a}, \mathbf{b}$ was investigated by the reaction with $9 H$-purin-6-amine (7d) and morpholine (7a) as the nucleophiles under the above conditions (Table 4). As it was expected, single regioisomers 13a,b with 1,2-anti-2,3-anti-configuration (Table 4, entries 1 and 2) were obtained. $\mathrm{C}(1) \mathrm{H}-\mathrm{C}(2) \mathrm{H}, \mathrm{C}(1) \mathrm{H}-$ $\mathrm{OH}, \mathrm{C}(1) \mathrm{H}-\mathrm{C}(5) \mathrm{H}$ COSY correlations and $\mathrm{C}(2) \mathrm{H}-\mathrm{C}(5) \mathrm{H}$, $\mathrm{C}(2) \mathrm{H}-\mathrm{OH}, \mathrm{C}(5) \mathrm{H}-\mathrm{OH}$ NOEs demonstrated that product $\mathbf{1 3 b}$ has the structure shown in Table 4. The presence of $\mathrm{C}(2) \mathrm{H}$ $\mathrm{C}(5) \mathrm{H}$ and $\mathrm{C}(1) \mathrm{H}-\mathrm{NCH}_{3}$ NOEs were supportive of the assigned configuration of 13a (Supporting Information File 2). The ring opening reaction of epoxide $\mathbf{6 b}$ with $9 H$-purin-6-amine (7d) in the presence of $\mathrm{Cs}_{2} \mathrm{CO}_{3}$ (Table 4, entry 2) showed the higher level of regioselectivity in comparison with the regioselective

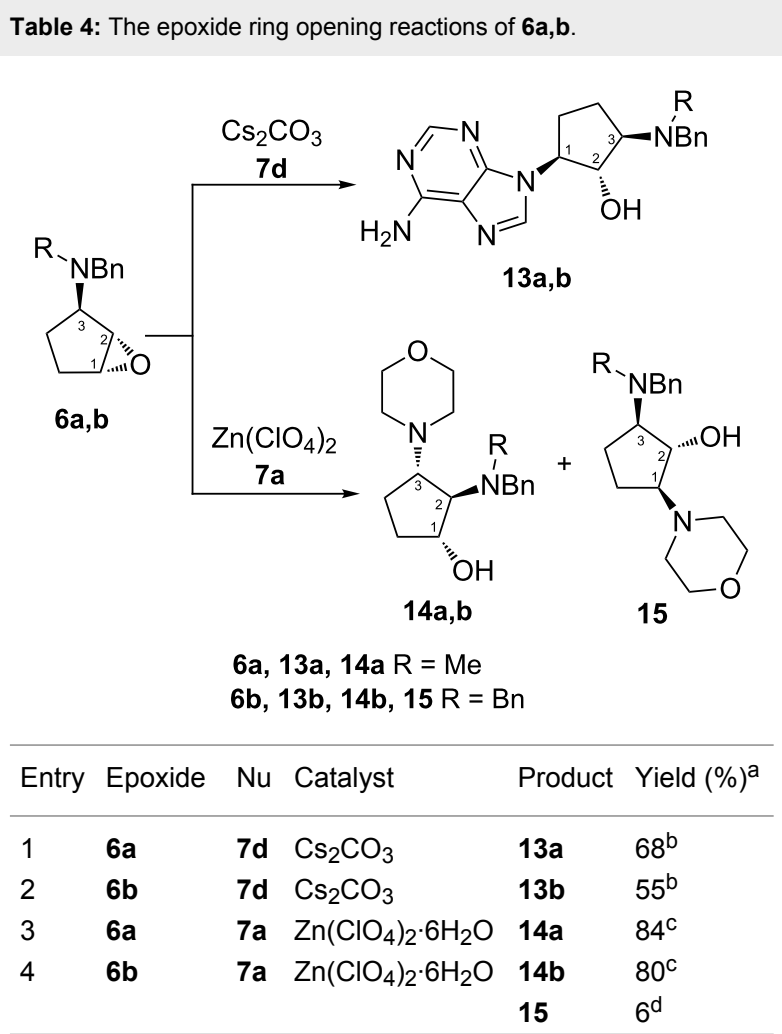

alsolated yield. ${ }^{\mathrm{b}}$ Reagents and conditions: $5.0 \mathrm{mmol}$ epoxide, $10.0 \mathrm{~mol} \%$ catalyst, $6.5 \mathrm{mmol}$ nucleophile, DMSO $(10 \mathrm{~mL}), 120^{\circ} \mathrm{C}$, $2 \mathrm{~h}$. ' Reagents and conditions: $5.0 \mathrm{mmol}$ epoxide, $10.0 \mathrm{~mol} \%$ catalyst, $6.5 \mathrm{mmol}$ nucleophile, neat, $100{ }^{\circ} \mathrm{C}, 2 \mathrm{~h}$. ${ }^{\mathrm{d}}$ Regioisomeric ratio (14b:15) $-12: 1$.

outcome for epoxide $\mathbf{3 b}$ (Table 2, entry 7), which can be interpreted as a result of dominance of steric over electronic factors in the case of epoxides $\mathbf{6 a}, \mathbf{b}$. 
A bulky $N, N$-disubstituted amino group is prone to adopt a pseudoequatorial orientation. In basic conditions, the nucleophile (9H-purin-6-amine (7d)) attacks the oxirane carbon atom from the side of the carbocyclic ring where the $N, N$-disubstituted amino group is located, and this precludes the approach of the nucleophile to the $\mathrm{C} 2$ carbon atom because of sterical hindrance. Thus, $\mathrm{C} 1$ of $\mathbf{6 a}, \mathbf{b}$ is the favoured site for the nucleophilic attack, which gives rise to the formation of products 13a,b with essentially complete regioselectivity (Table 4, entries 1 and 2). Surprisingly, aminolysis of substrates $\mathbf{6 a} \mathbf{a}, \mathbf{b}$ under Lewis acid-catalyzed conditions resulted mostly in the formation of regioisomers $\mathbf{1 4 a , b}$ (Table 4, entries 3 and 4), while the target isomer $\mathbf{1 5}$ was obtained only from epoxide $\mathbf{6 b}$, as the minor product in $6 \%$ yield (Table 4 , entry 4 ). Aminocyclopentanols 14a,b provided quite similar ${ }^{1} \mathrm{H}$ NMR spectra, and methine protons showed similar multiplicity patterns. For example, the resonance corresponding to $\mathrm{C}(2) \mathrm{H}$ of $\mathbf{1 4 a}$ appeared as a doublet of doublets $(J=7.0$ and $4.4 \mathrm{~Hz})$ centered at $\delta 2.84$, while the signal corresponding to $\mathrm{C}(2) \mathrm{H}$ of $\mathbf{1 4 b}$ also appeared as a doublet of doublets $(J=7.3$ and $4.3 \mathrm{~Hz})$ centered at $\delta$ 2.92. The structure and the relative configuration of $\mathbf{1 4 a , b}$ were unambiguously confirmed by the presence of $\mathrm{C}(1) \mathrm{H}$ $\mathrm{C}(2) \mathrm{H}, \mathrm{C}(1) \mathrm{H}-\mathrm{OH}, \mathrm{C}(2) \mathrm{H}-\mathrm{C}(3) \mathrm{H} \mathrm{COSY}$ and $\mathrm{C}(1) \mathrm{H}-\mathrm{C}(3) \mathrm{H}$, $\mathrm{C}(2) \mathrm{H}-\mathrm{OH}, \mathrm{C}(3) \mathrm{H}-\mathrm{CH}_{2} \mathrm{Ph}$ NOESY correlations observed in $2 \mathrm{D}$ spectra. The structure of $\mathbf{1 5}$ was determined by the analysis of 2D NMR spectra by analogy with that of $\mathbf{1 3 b}$ (Supporting Information File 2).

These results are in contrast to the outcome of the ring opening reactions of epoxides $\mathbf{3 a}, \mathbf{b}$, and this may be explained by the formation of $\mathbf{1 4 a , b}$ via the aziridimium intermediate 17. Based on earlier results [44], a mechanism of this transformation was hypothesized as shown in Scheme 2. The intermediate $\mathbf{1 7}$ is formed after the intramolecular rearrangement of intermediate 16 formed from $\mathrm{Zn}\left(\mathrm{ClO}_{4}\right)_{2}$-catalyzed $\mathrm{C}-\mathrm{O}$ bond cleavage followed by the attack of the $N, N$-disubstituted amino moiety towards $\mathrm{C} 2$. The approach of the $N, N$-disubstituted amino group to $\mathrm{C} 2$ would be more favorable than that of the nucleophile (morpholine) to either oxirane carbon atoms. Therefore, the nucleophilic attack is subsequent to the formation of the aziridinium ring, which is consistent with our experimental results.

\section{Conclusion}

In summary, we have optimized the reaction conditions of epoxide ring opening of epoxides $\mathbf{3 a}, \mathbf{b}$ and $\mathbf{6} \mathbf{a}, \mathbf{b}$ with a variety of amines to give the corresponding diaminocyclopentanols in good yields. It has been shown that using $\mathrm{Zn}\left(\mathrm{ClO}_{4}\right)_{2} \cdot 6 \mathrm{H}_{2} \mathrm{O}$ under solvent-free conditions and $\mathrm{Cs}_{2} \mathrm{CO}_{3}$ in DMSO is preferable to the ring opening of di- $N$-protected cyclopentanamine epoxides. We have highlighted the influence of the nature of the $N, N$-disubstituted amino moiety and the orientation of the oxirane ring on the stereo- and regioselective outcomes. Aminolysis of epoxides $\mathbf{3 a} \mathbf{a}, \mathbf{b}$ is mainly dictated by electronic bias to afford the corresponding $\mathrm{C} 1$ adducts for $\mathbf{3 a}$ and the mixture of $\mathrm{C} 1$ and $\mathrm{C} 2$ adducts in the ratio $2: 1$ for $\mathbf{3 b}$. The treatment of epoxides 6a,b with $9 H$-purin-6-amine (7d) under basecatalyzed conditions gives $\mathrm{C} 1$ adducts as the sole products. Thus, the nucleophilic attack of the amine towards the $\mathrm{C} 2$ oxirane carbon atom can be controlled by steric constraints, and it is obvious that the bulky $N, N$-dibenzylamino moiety of epoxide $\mathbf{6 b}$ impedes the formation of the corresponding $\mathrm{C} 2$ adduct due to the steric hindrance. Application of Lewis acid as a catalyst for the ring opening reactions of $\mathbf{6 a}, \mathbf{b}$ provides an alternative mechanism that involves the formation of aziridinium intermediate 17. As a result, regioisomers 14a,b were obtained as the major products.

\section{Supporting Information}

\section{Supporting Information File 1}

Experimental and characterization data.

[http://www.beilstein-journals.org/bjoc/content/ supplementary/1860-5397-10-262-S1.pdf]

\section{Supporting Information File 2}

Copies of ${ }^{1} \mathrm{H}$ and ${ }^{13} \mathrm{C}$ NMR spectra.

[http://www.beilstein-journals.org/bjoc/content/ supplementary/1860-5397-10-262-S2.pdf]

\section{Acknowledgements}

The present research was financially supported by New Scientific Technologies LLC. We thank Zelinski Organic Chemistry

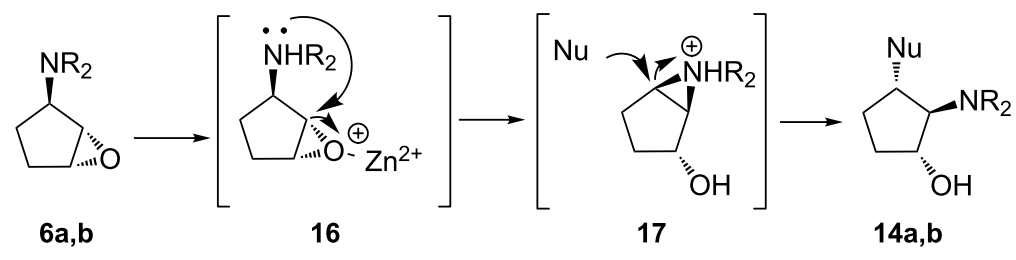


Institute for assistance in obtaining HRMS data. We are also grateful to Dr. A. Mazurov for helpful discussions regarding this work.

\section{References}

1. Mehta, G.; Lakshminath, S.; Talukdar, P. Tetrahedron Lett. 2002, 43, 335-338. doi:10.1016/S0040-4039(01)02125-6

2. Magnet, S.; Blanchard, J. S. Chem. Rev. 2005, 105, 477-498. doi:10.1021/cr0301088

3. Dey, R. T.; Sarkar, T. K. J. Org. Chem. 2010, 75, 4521-4529. doi:10.1021/jo100724w

4. Cong, X.; Liao, Q.-J.; Yao, Z.-J. J. Org. Chem. 2004, 69, 5314-5321. doi:10.1021/jo0496547

5. Pandey, G.; Tiwari, K. N.; Puranik, V. G. Org. Lett. 2008, 10, 3611-3614. doi:10.1021/ol801381t

6. Sakairi, N.; Hayashida, M.; Amano, A.; Kuzuhara, H. J. Chem. Soc., Perkin Trans. 1 1990, 1301-1313. doi:10.1039/p19900001301

7. Busscher, G. F.; Rutjes, F. P. J. T.; van Delft, F. L. Chem. Rev. 2005, 105, 775-792. doi:10.1021/cr0404085

8. Kapeller, H.; Baumgartner, H.; Marschner, C.; Pucher, R.; Griengl, H. Monatsh. Chem. 1997, 128, 953-960. doi:10.1007/BF00807105

9. Hatton, W.; Arosio, D.; Re, M.; Giudici, D.; Bernardi, A.; Seneci, P. C. R. Chim. 2010, 13, 1284-1300. doi:10.1016/j.crci.2009.11.004

10. Somu, R. V.; Wilson, D. J.; Bennett, E. M.; Boshoff, H. I.; Celia, L.; Beck, B. J.; Barry, C. E., III; Aldrich, C. C. J. Med. Chem. 2006, 49, 7623-7635. doi:10.1021/jm061068d

11. Bergmeier, S. C. Tetrahedron 2000, 56, 2561-2576. doi:10.1016/S0040-4020(00)00149-6

12. Chattopadhyay, S. K.; Bandyopadhyay, A. Tetrahedron Lett. 2011, 52, 3942-3944. doi:10.1016/j.tetlet.2011.05.103

13. Verhelst, S. H. L.; Wennekes, T.; van der Marel, G. A.; Overkleeft, H. S.; van Boeckel, C. A. A.; van Boom, J. H. Tetrahedron 2004, 60, 2813-2822. doi:10.1016/j.tet.2004.01.063

14. Trapero, A.; Alfonso, I.; Butters, T. D.; Llebaria, A. J. Am. Chem. Soc. 2011, 133, 5474-5484. doi:10.1021/ja111480z

15. Calvani, F.; Crotti, P.; Gardelli, C.; Pineschi, M. Tetrahedron 1994, 50, 12999-13022. doi:10.1016/S0040-4020(01)81219-9

16. Chini, M.; Crotti, P.; Macchia, F. Tetrahedron Lett. 1990, 31, 4661-4664. doi:10.1016/S0040-4039(00)97701-3

17. Zeynizadeh, B.; Sadighnia, L. Bull. Korean Chem. Soc. 2010, 31, 2644-2648. doi:10.5012/bkcs.2010.31.9.2644

18. Fan, R.-H.; Hou, X.-L. Tetrahedron Lett. 2003, 44, 4411-4413. doi:10.1016/S0040-4039(03)00943-2

19. Arbelo, D. O.; Prieto, J. A. Tetrahedron Lett. 2002, 43, 4111-4114. doi:10.1016/S0040-4039(02)00739-6

20. Hoveyda, A. H.; Evans, D. A.; Fu, G. C. Chem. Rev. 1993, 93, 1307-1370. doi:10.1021/cr00020a002

21. Asensio, G.; Boix-Bernardini, C.; Andreu, C.; González-Núñez, M. E.; Mello, R.; Edwards, J. O.; Carpenter, G. B. J. Org. Chem. 1999, 64, 4705-4711. doi:10.1021/jo982512q

22. Davies, S. G.; Long, M. J. C.; Smith, A. D. Chem. Commun. 2005, 4536-4538. doi:10.1039/b509088a

23. Aciro, C.; Claridge, T. D. W.; Davies, S. G.; Roberts, P. M.; Russell, A. J.; Thomson, J. E. Org. Biomol. Chem. 2008, 6, 3751-3761. doi:10.1039/b808811j

24. Zhao, S.; Freeman, J. P.; Chidester, C. G.; VonVoigtlander, P. F.; Mizsak, S. A.; Szmuszkovicz, J. J. Org. Chem. 1993, 58, 4043-4048. doi:10.1021/jo00067a042
25. Threadgill, M. D.; Webb, P. J. Chem. Soc., Chem. Commun. 1991, 269-271. doi:10.1039/c39910000269

26. Serrano, P.; Llebaria, A.; Delgado, A. J. Org. Chem. 2002, 67, 7165-7167. doi:10.1021/jo0261146

27. Chini, M.; Crotti, P.; Favero, L.; Macchia, F.; Pineschi, M. Tetrahedron Lett. 1994, 35, 433-436. doi:10.1016/0040-4039(94)85073-9

28. Brennan, M.; Claridge, T. D. W.; Compton, R. G.; Davies, S. G.; Fletcher, A. M.; Henstridge, M. C.; Hewings, D. S.; Kurosawa, W.; Lee, J. A.; Roberts, P. M.; Schoonen, A. K.; Thomson, J. E. J. Org. Chem. 2012, 77, 7241-7261. doi:10.1021/jo3010556

29. Bond, C. W.; Cresswell, A. J.; Davies, S. G.; Fletcher, A. M.; Kurosawa, W.; Lee, J. A.; Roberts, P. M.; Russell, A. J.; Smith, A. D.; Thomson, J. E. J. Org. Chem. 2009, 74, 6735-6748. doi:10.1021/jo9012783

30. Swamy, N. R.; Kondaji, G.; Nagaiah, K. Synth. Commun. 2002, 32, 2307-2312. doi:10.1081/SCC-120006000

31. Kim, B.-H.; Piao, F.; Lee, E.-J.; Kim, J.-S.; Jun, Y.-M.; Lee, B.-M. Bull. Korean Chem. Soc. 2004, 25, 881-888. doi:10.5012/bkcs.2004.25.6.881

32. Pujala, B.; Rana, S.; Chakraborti, A. K. J. Org. Chem. 2011, 76, 8768-8780. doi:10.1021/jo201473f

33. Sabitha, G.; Reddy, G. S. K. K.; Reddy, K. B.; Yadav, J. S. Synthesis 2003, 2298-2300. doi:10.1055/s-2003-41070

34. Jacobsen, E. N. Acc. Chem. Res. 2000, 33, 421-431. doi:10.1021/ar960061v

35. Chakraborti, A. K.; Kondaskar, A. Tetrahedron Lett. 2003, 44 , 8315-8319. doi:10.1016/j.tetlet.2003.09.046

36. Serrano, P.; Llebaria, A.; Vázquez, J.; de Pablo, J.; Anglada, J. M.; Delgado, A. Chem. - Eur. J. 2005, 11, 4465-4472. doi:10.1002/chem.200401270

37. Pujala, B.; Chakraborti, A. K. J. Org. Chem. 2007, 72, 3713-3722. doi:10.1021/jo062674j

38. Ollevier, T.; Nadeau, E. Tetrahedron Lett. 2008, 49, 1546-1550. doi:10.1016/j.tetlet.2007.12.100

39. Flessner, T.; Doye, S. J. Prakt. Chem. 1999, 341, 186-190. doi:10.1002/(SICI)1521-3897(199902)341:2<186::AID-PRAC186>3.0. CO;2-6

40. Fink, D. M. Synlett 2004, 2394-2396. doi:10.1055/s-2004-832836

41. Birajdar, S. S.; Hatnapure, G. D.; Keche, A. P.; Kamble, V. M. J. Chem. Pharm. Res. 2013, 5, 583-589.

42. Caron, M.; Sharpless, K. B. J. Org. Chem. 1985, 50, 1557-1560. doi:10.1021/jo00209a047

43. Chong, J. M.; Sharpless, K. B. J. Org. Chem. 1985, 50, 1560-1563. doi:10.1021/jo00209a048

44. Aciro, C.; Davies, S. G.; Roberts, P. M.; Russell, A. J.; Smith, A. D.; Thomson, J. E. Org. Biomol. Chem. 2008, 6, 3762-3770. doi:10.1039/b808812h 


\section{License and Terms}

This is an Open Access article under the terms of the Creative Commons Attribution License

(http://creativecommons.org/licenses/by/2.0), which permits unrestricted use, distribution, and reproduction in any medium, provided the original work is properly cited.

The license is subject to the Beilstein Journal of Organic Chemistry terms and conditions:

(http://www.beilstein-journals.org/bjoc)

The definitive version of this article is the electronic one which can be found at:

doi:10.3762/bjoc. 10.262 